This item was submitted to Loughborough's Research Repository by the author.

Items in Figshare are protected by copyright, with all rights reserved, unless otherwise indicated.

\title{
Seasonal effects of food quality and temperature on body stoichiometry, biochemistry, and biomass production in Daphnia populations
}

PLEASE CITE THE PUBLISHED VERSION

https://doi.org/10.1002/Ino.10803

\section{PUBLISHER}

(C) Association for the Sciences of Limnology and Oceanography. Published by Wiley

\section{VERSION}

AM (Accepted Manuscript)

\section{PUBLISHER STATEMENT}

This work is made available according to the conditions of the Creative Commons Attribution-NonCommercialNoDerivatives 4.0 International (CC BY-NC-ND 4.0) licence. Full details of this licence are available at: https://creativecommons.org/licenses/by-nc-nd/4.0/

\section{LICENCE}

CC BY-NC-ND 4.0

\section{REPOSITORY RECORD}

Prater, Clay, Nicole D. Wagner, and Paul C. Frost. 2019. "Seasonal Effects of Food Quality and Temperature on Body Stoichiometry, Biochemistry, and Biomass Production in Daphnia Populations". figshare. https://hdl.handle.net/2134/36450. 
1 Running title: Diet and temperature effects on Daphnia

2

3

4 Seasonal effects of food quality and temperature on body stoichiometry, biochemistry, and 5 biomass production in Daphnia populations

6

7

8

Clay Prater $^{1 \dagger}$, Nicole D. Wagner ${ }^{1}$, and Paul C. Frost ${ }^{2}$

9

10

$11{ }^{1}$ Environmental and Life Science Graduate Program, Trent University, Peterborough Ontario

$122^{2}$ Department of Biology, Trent University, Peterborough Ontario

$13{ }^{\dagger}$ contact information of corresponding author, mail to: prater.clay@ gmail.com 705-748-1011 ext.

147676

15

16

17 Author Contributions: CP, NDW, and PCF conceived and designed the experiments. NDW and

18 CP collected and processed samples. CP and PCF analyzed the data and wrote the manuscript.

19

20

21

22

23

24 Keywords: ecological stoichiometry, metabolism, zooplankton, nutrient 
Food quality and temperature can affect zooplankton production in lakes by altering

27 organismal metabolism. However, the influence of these factors on consumer nutritional

28 physiology and population biomass remains relatively understudied in natural populations. Here,

29 we examined seasonal changes in body stoichiometry, biochemistry, and population biomass in

30 two Daphnia species collected from two separate lakes differing in dietary phosphorus (P)

31 supply. Food quality, measured as seston carbon:P (C:P) ratios, varied throughout the study in

32 each lake, and water temperatures generally increased across the growing season. Daphnid

33 elemental composition was correlated with food quality in both populations, but relationships

34 between daphnid body stoichiometry and temperature were consistently stronger as Daphnia

35 body C:P ratios and content of major biochemical pools declined simultaneously throughout the summer, which largely coincided with increased water temperatures. Warmer temperatures were

37 associated with relaxed \%P-RNA coupling as daphnid body RNA content declined and P content remained relatively high. These responses combined with temperature related decreases in Daphnia body \%lipids and \%C appeared to explain declines in daphnid body C:P ratios in both

40 lakes over the growing season. Seasonal changes in population biomass were related to both food

41 quality and water temperature in the lower nutrient lake. Biomass production under more

42 eutrophic conditions however was unrelated to food quality and was instead associated with

43 seasonal temperature changes in the higher nutrient lake. Overall, our study shows that seasonal

44 changes in temperature and resource quality may differentially affect consumer stoichiometry and biomass production in lake ecosystems by altering consumer elemental metabolism. 


\section{Introduction}

Freshwater zooplankton assemblages can show considerable phenological changes in

50

51

52

53

54

55

56

57

58

59

60

61

62

63

64

65

66

67

68

69

70

biomass production in temperate lake ecosystems (Sommer et al. 1986; Pantel et al. 2014). These

seasonal dynamics have traditionally been considered to be predominantly regulated by

biological constraints such as predation and food quantity (McCauley \& Kalff 1981; Carpenter et

al. 1985; Sommer et al. 1986). In addition, recent studies have demonstrated the importance of elemental food quality in controlling zooplankton production through its effects on consumer nutritional physiology and community biomass (Elser et al. 1998, 2003; Hessen et al. 2005;

Sommer et al. 2012). Experimental work has also found that food quality can interact with other temporally dynamic variables such as temperature to alter consumer growth and metabolic rates in laboratory environments (Makino et al. 2011; McFeeters and Frost 2011). Despite considerable seasonal differences in dietary elemental composition and temperature in temperate lakes (Kreeger et al. 1997; Hessen et al. 2005), their relative influence on consumer metabolism and population dynamics in natural assemblages remains poorly understood. Here, we examine how zooplankton consumer (Daphnia spp.) body stoichiometry, biochemistry, and population biomass relate to temporal changes in food quality and temperature in two different lake ecosystems.

Nutrient availability differs widely within and among aquatic habitats (Elser et al. 2000a; Sterner et al. 2008), and food elemental content is a well-known factor influencing consumer nutritional physiology and life-history (Frost et al. 2005; Wagner et al. 2013). Imbalances between the proportional supplies of key dietary elements like carbon $(\mathrm{C})$, nitrogen $(\mathrm{N})$, and phosphorus $(\mathrm{P})$ and consumer metabolic demands can alter the synthesis of major macromolecules such as lipids, proteins, and nucleic acids, respectively (Elser et al. 1996; 
71 Wagner et al. 2015). As these biochemical pools are tied to consumer elemental composition

72 (Elser et al. 1996), poor food quality could indirectly affect consumer body stoichiometry by

73 altering their elemental metabolism. Specifically, the growth hypothesis states that dietary P-

74 limitation can slow the production of P-rich ribosomal RNA in animals and increase their body

75 N:P ratios (Elser et al. 2003; Loladze and Elser 2011). These metabolic changes are further

76 known to reduce individual growth, reproduction, and survivorship rates (Sterner et al. 1993;

77 Frost et al. 2005), which suggests that poor food quality could ultimately lead to decreased

78 biomass production in consumer populations (Loladze et al. 2000). Thus, elemental imbalances

79 between producers and consumers represent potentially strong controls on aquatic food webs by

80 regulating the proportion and amount of elements found within the consumer trophic level

81 (Andersen 1997; Cebrian et al. 2009).

82 In addition to food quality, temperature also affects consumer nutrient metabolism.

83 Within biologically relevant ranges, temperature drives exponential changes in organismal

84 metabolic rates (Gillooly et al. 2001; Brown et al. 2004), which in turn influence animal

85 biochemical composition and elemental content (Woods et al. 2003; Bullejos et al. 2014). For

86 example, higher temperatures can reduce cellular RNA and P demands due to increased

87 ribosomal translational efficiencies (Sievers et al. 2004; Toseland et al. 2013) and decrease body

88 lipid stores by increasing C respiration (Evjemo et al. 2001; McFeeters and Frost 2011; Alcaraz

89 et al. 2013) leading to proportional changes in consumer body C:P ratios. Further, by influencing

90 consumer life-history trait expression and elemental composition, temperature can also affect

91 population growth rates and regulate elemental flows through ecosystems (Petchey et al. 1999;

92 Savage et al. 2004). In all, temperature and food quality play key roles in shaping consumer

93 metabolism, and changes in these variables may have cascading effects on organismal life- 
94 history, body stoichiometry, and population dynamics in aquatic ecosystems (Hessen et al. 2005;

95 Cross et al. 2015).

In this study, we documented weekly variation in daphnid body elemental composition,

97 gross biochemistry, and biomass production of two daphnid species (D. pulicaria and D. mendotae) collected from two separate lakes across a summer growing season. As these species

99 show little overlap in our study region and are predominantly found in low and high $\mathrm{P}$ 100 environments, respectively (Prater et al. 2017), we examined changes in each species

101 independently. Food quality and temperature changed seasonally in each lake allowing us to 102 compare the compare their relative effects on 1) daphnid elemental-biochemical relationships 103 and 2) biomass production within each population. By focusing on two elements and their major 104 molecular pools with well-known connections to daphnid nutritional physiology (P-RNA) and 105 that account for the majority of consumer biomass (C-lipids), we provide in situ observations to 106 better understand the effects of temperature and dietary nutrient supply on consumer elemental 107 metabolism within the context of stoichiometric theory.

108 Methods

Study Sites. We sampled Daphnia populations from two lakes that are geographically close ( 40 km apart) but are found in two distinct ecoregions in south central Ontario. Wolf Lake 111 is located in the Kawartha Highland Provincial Park on the southern edge of the Canadian Shield 112 where landuse is mostly forested with little to moderate shoreline development (Hicks and Frost 113 2011). Pigeon Lake is in the Kawartha Lakes region, which is located just south of the Canadian 114 Shield. This area is characterized by significant agricultural landuse ( $50 \%)$ and high lake shore 115 residential development (Crins et al. 2009). These lakes were chosen due to their differences P 116 supply and trophic state (Suppl. Table 1) as Wolf Lake is considered to be an oligo-mesotrophic 
117 lake and Pigeon Lake is meso-eutrophic (sensu, Carlson 1977). In addition, each site is also

118 inhabited by a different species of Daphnia (Pigeon: D. mendotae and Wolf: D. pulicaria, Prater 119 et al. 2017).

$120 \quad$ Field Sampling. Lake sampling began immediately after ice off, which occurred 2 weeks

121 earlier in Pigeon Lake than Wolf Lake. Lakes were sampled weekly from May through

122 September for a total of 22 and 20 weeks, respectively. This time span roughly represents a

123 normal growing season in many temperate regions of the northern hemisphere. Water samples

124 for total phosphorus (TP) and seston analyses (stoichiometry and biomass) were collected at the

125 surface of the water column and $1 \mathrm{~m}$ from bottom $(8-10 \mathrm{~m})$ using a Van Dorn sampler. These

126 samples were poured into acid-washed 4 L carboys and transported back to the lab on ice.

127 Quantitative Daphnia biomass samples were collected by taking fixed-depth vertical tows at 128 these sites. These samples were rinsed into $500 \mathrm{ml}$ plastic bottles and kept cool at $\sim 4^{\circ} \mathrm{C}$ during 129 transport. Temperature depth profiles were measured during each collection period (YSI Pro20, 130 Yellow Springs, OH), and lakes were sampled at roughly the same time of the day (1000-1200h) 131 to minimize the influence of diurnal temperature fluctuations.

132 Sample Processing and Preservation: In the laboratory, we saved whole water samples

133 for $\mathrm{TP}$ analysis at $4^{\circ} \mathrm{C}$ until processing. We pre-filtered water samples for seston analysis with 80 $134 \mu \mathrm{m}$ mesh to remove inedible particles and then filtered the remaining suspended materials onto 135 pre-ashed $0.7 \mu \mathrm{m} \mathrm{GF/F}$ glass fiber filters. Samples for stoichiometric analysis of surface and 136 bottom samples ( $\mathrm{n}=2 \mathrm{CN}$ and $\mathrm{n}=2 \mathrm{P}$ for each) were dried at $60^{\circ} \mathrm{C}$ and stored at $20^{\circ} \mathrm{C}$, and 137 chlorophyll a ( $\mathrm{Chl} a, \mathrm{n}=2$ for each) was frozen and stored in the dark at $-20^{\circ} \mathrm{C}$ until analysis. 138 Between 5-10 daphnids were pooled into 5 separate samples for elemental analysis $(\mathrm{n}=5 \mathrm{CN}$ and $139 \mathrm{n}=5 \mathrm{P}$ analytical replicates). Animals were rinsed twice with deionized water, placed into pre- 
140 weighed tins, dried at $60^{\circ} \mathrm{C}$, and desiccated prior to weighing on a microbalance $( \pm 1 \mu \mathrm{g}$; Mettler-

141 Toledo, Markham, ON). For gross biochemical analysis, daphnids were also rinsed and saved in

142 separate $1.5 \mathrm{ml}$ vials for each analysis. Lipid samples (10-20 pooled individuals, $\mathrm{n}=5$ samples)

143 were immediately flash-frozen using liquid nitrogen, stored at minus $-80^{\circ} \mathrm{C}$, and lyophilized. For

144 RNA samples, we measured lengths of 10 individuals (from the top of the eyespot to the base of

145 the tail), placed each animal into a numbered vial, added $100 \mu 1$ RNA-later (ThermoFisher,

146 Burlington, $\mathrm{ON}$ ) to each vial, flash-froze all samples, and stored them at $-80^{\circ} \mathrm{C}$. Only live

147 animals were preserved for stoichiometric and biochemical analysis to prevent elemental

148 leaching and molecular degradation. Samples used to estimate daphnid biomass ( $\mathrm{n}=3$ tows) were

149 divided using a zooplankton splitting wheel ( $\mathrm{n}=2$ analytical replicates for each tow) and were

150 preserved using a 4\% sugar buffered formalin solution (Haney and Hall 1973).

151

152 measured on an elemental analyzer (Vario EL III, Elementar Inc. Mt. Laurel, NJ). Seston P, 153 water TP, and daphnid P content were measured after persulfate digestion through molybdate154 blue ascorbic acid colorimetry (APHA 1992) and absorbance spectroscopy (Cary-50, Varian, 155 Palo Alto, CA). We then used daphnid masses to calculate \%, $\mathrm{N}$, and $\mathrm{P}$ for each animal and 156 converted all elemental ratios to molar ratios.

157 Prior to biochemical analyses we first weighed lyophilized Daphnia (lipids) or used 158 length/mass regressions (RNA, see below for details) to estimate total animal dry mass. All 159 biochemical analyses were then conducted using procedures from Wagner et al. (2015), and to 160 ensure proper extraction and analysis for all fractions, we included the same $D$. magna clone 161 used in that study as an internal control in each run. We analyzed total lipid content by first 162 homogenizing Daphnia tissues using a motorized pestle in 2:1 chloroform:methanol ( $v / v)$. Then, 
163 we followed a sulfophosphovanillan (SPV) heat block procedure to extract the lipid fraction

164 (Gardner et al. 1985). Standards were prepared by dissolving cholesterol in 2:1 chloroform:

165 methanol $(v / v)$, and samples and standards were analyzed with a spectrophotometer. Total

166 nucleic acid content (DNA/RNA) was analyzed as described by Gorokhova et al. (2002).

167 Daphnia were rinsed to remove residual RNA-later and homogenized in $200 \mu$ l of TE buffer.

168 Then, we pippetted $50 \mu \mathrm{l}$ of daphnid homogenate two 2 separate tubes, added $50 \mu 1$ of $5 \mu \mathrm{g} \mathrm{L}^{-1}$

169 DNAse and RNase to separate tubes, and incubated them at $37^{\circ} \mathrm{C}$ for $15 \mathrm{~min}$. We ran samples

170 and RNA/DNA standards using a RiboGreen fluorometric analysis on a microplate reader

171 (Synergy HT, Biotech, Winooski, VT). We divided total biochemical concentrations by total

172 animal mass to calculate \%RNA and \%Lipids. We also estimated the proportion of daphnid body

$173 \%$ P in the RNA pool (\%P-RNA) by assuming a fixed P content (9\%) for RNA (Elser et al. 2003;

174 Acharya et al. 2004) and dividing RNA bound P by total body \%P.

175 Daphnia biomass estimates. Daphnid biomass estimates were made with methods

176 described in McCauley (1984). Briefly, we divided each tow replicate ( $n=3)$ into analytical

177 subsamples $(\mathrm{n}=2)$, and for each subsample we counted individuals in 5 separate $1 \mathrm{ml}$ samples on

178 a Sedgewick-Rafter slide using a compound microscope. While counting, we also measured the

179 body lengths of at least 25 individuals using digital photo software (iSolution, iMTechnology,

180 Coquitlam, BC). Length-mass relationships for individual species from each lake were

181 determined by growing field-caught Daphnia to different $0.1 \mathrm{~mm}$ size classes $(\mathrm{n}=10-20$ per

182 class) in the lab while feeding them lab cultured algae (Scenedesmus Obliquus Canadian

183 Physiological Culture Centre strain 10). Pooled individuals for each size class were then dried at

$18460^{\circ} \mathrm{C}$, desiccated, and weighed using a microbalance. We then used power functions to estimate

185 the mass of each daphnid from length measurements $\left(\mathrm{R}^{2}=0.96-0.98\right)$ and multiplied the mean 
Daphnia mass by the total number of individuals found in each $1 \mathrm{ml}$ sample to obtain a biomass estimate for each subsample. Finally, we scaled these mass estimates up from the $1 \mathrm{ml}$ samples to the volume of water sampled in each tow $\left(\mu \mathrm{g} \mathrm{L}{ }^{-1}\right)$.

Statistical Analyses. Before conducting temporal analyses, we plotted temperature depth profiles and top and bottom seston stoichiometry values for each lake. Pigeon Lake was well mixed for most of the year, and seston C:P values were similar in top and bottom waters. Therefore, we used integrated seston stoichiometry values and water column temperature measurements in our subsequent data analyses. In contrast, Wolf Lake showed seasonal stratification and had systematically higher C:P ratios in the top waters (Fig. 1A). As we could not track daphnid diel migration patterns and thus could not determine their precise daily food quality regimes, we analyzed relationships between daphnid response variables and top, bottom, and integrated food $\mathrm{C}: \mathrm{P}$ and measurements separately.

All other data were also visualized using scatter plots. Temperature and seston stoichiometry were highly skewed due to our sampling regime, and we also detected non-linear and non-monotonic trends in the data. As traditional parametric time-series analysis methods were inappropriate, we estimated the strength of relationships between variables through a distance correlation (dcor) approach using the 'energy’ package in R (Rizzo and Szekely 2008; Székely and Rizzo 2009). This technique is similar to other traditional non-parametric correlational statistics such as Spearman's $(\rho)$ or Kendall's $(\tau)$. However, distance correlation does not assume monotonic relationships between variables, and the test statistic (D) is reported from $0-1$ with a value of 0 indicating a complete independence of two variables and values approaching 1 indicating stronger correlations. 
In general, daphnid correlations in Wolf Lake were more strongly related with top seston

209 C:P values than with bottom values (Suppl. Table 2). Although correlation strength differed

210 slightly between top and integrated measurements, relationships between these values and

211 daphnid responses were qualitatively similar. Therefore, our inferences do not change using

212 either measurement, and we report our Wolf Lake results using top seston C:P and temperature

213 values to minimize the influence of bottom waters on our analyses.

214 Results

215

Seasonal changes in food quality, temperature, and Daphnia elemental content. Seston

216 C:P ratios changed over the growing season and differed for most of the year between the two

217 lakes (Fig. 1A\&B). In general, seston stoichiometry in Wolf Lake was P poor and varied

218 considerably over the summer (c.v. $=40 \%)$, whereas Pigeon Lake seston was P rich throughout

219 the study and varied less (c.v.=19\%). Temperature regimes were similar in these lakes with a

220 peak in temperature occurring in mid-July (Fig. 1 C\&D). In both Wolf and Pigeon Lake, daphnid

221 body C:P ratios were relatively more constrained than their food resources (c.v.=10-12\%) and

222 declined steadily across the growing season (Fig. 1 E\&F).

223

Irrespective of lake and species, Daphnia body elemental composition was more strongly

224 correlated with temperature than food quality (Figs. 2\&3). In Wolf Lake, D. pulicaria body \%C

225 and C:P ratios were negatively related to seston C:P ratios and temperature. In contrast, daphnid

226 body \%P was positively correlated with seston C:P and increased with higher seasonal

227 temperatures. In Pigeon Lake, D. mendotae body \%C was positively correlated to seston C:P

228 ratios but declined precipitously at higher temperatures (Fig. 3 A\&B). Daphnid body P content

229 was not significantly related to seston C:P ratios and instead increased non-linearly with 
231 related to food quality and temperature with temperature effects showing relatively stronger 232 correlations.

Correlations between temperature, Daphnia biochemistry, and body stoichiometry.

234 Temperature effects on daphnid body stoichiometry seemed to be mediated by changes in their

235 biochemical and elemental metabolism. In both species, body \%RNA declined with higher

236 seasonal temperatures (Fig. 4 A\&B), but body \%P remained relatively high ( 1.2-1.6\%)

237 resulting in weak correlations between daphnid body \%P and RNA in Daphnia from both Wolf

238 and Pigeon Lakes (Fig. 4C\&D). These temperature related metabolic changes appeared to alter

239 organismal P investment into RNA production (Fig. 4E\&F) as reduced \%P-RNA ratios

240 corresponded with lower body C:P ratios in each study population. Similar to \%RNA, body lipid

241 content also decreased with higher seasonal temperatures in both daphnid species (Fig. 5A\&B).

242 However, unlike \%P-RNA relationships, daphnid body \%lipid was more strongly related to body

243 C content (Fig. 5C\&D), and reduced lipid stores corresponded with lower Daphnia body C:P

244 ratios in each population (Fig. 5E\&F).

Relationships between Daphnia biomass, food quality, and temperature. In Wolf Lake,

246 daphnid biomass displayed a large population increase soon after ice-off, which was quickly

247 followed by a rapid population decline (Fig. 6A). Population biomass remained near zero during

248 the middle of the growing season but was reestablished to moderate levels in the later summer

249 months. Daphnia biomass in this low P lake was related to both food quality and temperature

250 with the highest biomass occurring at low seston C:P ratios and moderate temperatures (Fig. 6

251 C\&E). In the more eutrophic Pigeon Lake, daphnid biomass also showed a large early season

252 spike, but biomass quickly decreased and remained low afterwards for the remainder of the study

253 (Fig. 6B). Biomass production was not significantly related to seston C:P ratios in this lake 
254 (Figure 6D) where daphnid biomass was instead correlated with temperature and peaked at

255 moderate temperatures (Figure 6F).

256 Discussion

257 In each study lake, Daphnia elemental composition was related to seasonal changes in

258 both food quality and temperature. However, we found negative correlations between seston C:P

259 and daphnid C:P in Wolf Lake and weak relationships between these variables in Pigeon Lake

260 suggesting that daphnid stoichiometry was poorly related to food quality overall. Instead,

261 temperature appeared to more strongly alter Daphnia elemental composition as body C:P

262 declined with higher summer temperatures. These changes were consistent with temperature

263 effects on daphnid biochemical pools as higher temperatures were associated with relaxed

264 coupling between body P and RNA content and reduced C-rich lipid stores. Although

265 temperature seemed to be mostly responsible for driving seasonal variation in Daphnia

266 stoichiometry, both temperature and food quality were related to total biomass production in 267 study lakes.

Seston and Daphnia stoichiometry varied seasonally within each lake. As in other

269 studies, we observed phenological changes in seston C:P ratios (Kreeger et al. 1997; Hessen et

270 al. 2005), which fell within previously documented measurements (C:P 100-800; Elser et al.

271 2000a; Sterner et al. 2008). Fine-scale (weekly) variation was also high in the low P Wolf Lake

272 due to differences in seston stoichiometry between the epi- and hypolimnion. While Daphnia

273 pulicaria body stoichiometry also changed temporally in Wolf Lake, their body stoichiometry

274 seemed to decouple from seston C:P as daphnid and seston C:P ratios were negatively correlated

275 across the growing season. Stoichiometric food quality was high for the entire study period in

276 Pigeon Lake (C:P <200) where Daphnia mendotae body C:P ratios were positively correlated 
277 with seston C:P, similar to patterns observed in other temperate lakes (DeMott et al. 2004).

278 However, this relationship was not as strong in our study due to extensive stoichiometric

279 variation in this taxon. Together, the decoupling of seston C:P and daphnid C:P in Wolf Lake 280 and weak relationships in Pigeon Lake suggest that food quality likely played a minor role in 281 shaping Daphnia body stoichiometry in both populations. Instead, seasonal declines in daphnid

$282 \mathrm{C}: \mathrm{P}$ appeared to be more connected to temperature effects on daphnid elemental composition and 283 biochemistry.

Temperature was strongly related to daphnid P and RNA content in field-caught animals.

285 Seasonal temperature increases were associated with linear increases in D. pulicaria body \% $\mathrm{P}$ in 286 Wolf Lake and non-linear responses in D. mendotae from Pigeon Lake. Our results resemble 287 those from a previous laboratory experiment showing species differences in body \%P across 288 temperature gradients (McFeeters and Frost 2011). But unlike this study, daphnid responses in 289 our lakes appeared to be mostly independent from food quality effects, suggesting that 290 organismal responses to temperature in natural populations are likely to be both context and 291 species dependent (Bullejos et al. 2014; Moody et al. 2017). Body RNA content declined in both 292 of our study species with increased temperatures, which is consistent with adaptive physiological 293 thermal responses commonly observed across many taxa in the wild (Woods et al., 2003).

294 However, relationships between daphnid body \%P and \%RNA were weak for D. mendotae and 295 were even negative in D. pulicaria suggesting that temperature unexpectedly modified consumer 296 nutrient metabolism in our lakes.

Investment of P into Daphnia RNA pools declined substantially with higher seasonal temperatures. This observation contrasts with many studies that have found consistent positive relationships between organismal body \%P and \%RNA (Elser et al., 2000; Bullejos et al., 2014; 
Zhang et al., 2016). Our results could thus at first glance seem to contradict the central premise of the growth rate hypothesis. However, this hypothesis as currently formulated is most applicable to consumers experiencing P-limitation and growing at the same temperature (Elser et al. 2003; Moody et al. 2017). Since relaxed coupling of daphnid body \%P and \%RNA has been documented outside of these narrow set of conditions (Elser et al. 2003; Acharya et al. 2004; Wagner et al. 2015), temperature mediated changes in elemental-biochemical coupling may explain the weak relationships between Daphnia C:P and seston C:P in our study. As a majority of consumer body \%P is thought to be associated with ribosomal RNA (Elser et al. 1996), it remains unclear how Daphnia in our study maintained a high body \%P despite exhibiting reduced body RNA content. We can eliminate the possibility of increased investment into DNA since it was a relatively small component of daphnid biomass $(<0.4 \%$; Suppl. Fig. 1A\&B). As we did not measure additional P pools (e.g., phosphosugars, phospholipids), more work is required to identify the molecular form of the remaining unaccounted-for body $\% \mathrm{P}$. These studies should include other important elemental-biochemical relationships, such as body $\% \mathrm{~N}-$ protein content, which also seemed to be temperature dependent in our populations (Suppl. Fig. 1C\&D). Understanding how consumers regulate their nutrient metabolism across temperature gradients is clearly an important step towards the further integration of temperature effects into stoichiometric theory.

Seasonal changes in water temperature were also related to daphnid body $\mathrm{C}$ and lipid content. In both populations, we saw sharp declines in daphnid body $\% \mathrm{C}$, which corresponded to a reduction of $\sim 10-15 \%$ of their total body dry mass at higher temperatures. These changes were likely due to elevated metabolic rates (Darchambeau et al. 2003; McFeeters and Frost 2011), which have been shown to decrease Daphnia body lipid and C content (Zhang et al. 2016). We 
323 provide further support for this mechanism as we observed synchronous declines in C-rich

324 Daphnia body lipid stores and C:P ratios with higher seasonal temperatures in these two

325 ecologically distinct species. These changes along with altered P metabolism provide a likely

326 explanation for declines in Daphnia body C:P ratios across the growing season and highlight the

327 important role of temperature in shaping consumer elemental composition in field assemblages

328 (Bullejos et al. 2014).

329

Although temperature was strongly related to Daphnia stoichiometry in our study, it is

330 necessary to consider temperature effects within the hierarchy of other factors potentially

331 affecting animal C:P ratios in nature. Consumer body stoichiometry reflects the influence of a

332 number of environmental and biological factors that operate simultaneously across spatial and

333 temporal scales (Cherif et al. 2017). Within individuals (level-1; L1), consumer body

334 stoichiometry is proximately controlled by the biochemical/elemental content of its subcellular

335 components and body tissues (Elser et al. 1996). For instance, differences in the elemental

336 content of somatic vs. reproductive tissues such as eggs can alter daphnid body stoichiometry

337 and account for size-specific differences across developmental stages (Ventura and Catalan

338 2005; Frost et al. 2008). At an environmental-level (L2), variables that affect consumer

339 physiology, life-history, or behavior can alter the intake and investment of dietary elements at L1

340 (Frost et al. 2005). In addition to food quality, this list includes a suite of abiotic variables (e.g.,

341 light and $\mathrm{CO}_{2}$,), biotic factors such as food quantity and algal taxonomic composition, and food

342 web dependent factors such as predation and parasitism (Dickman et al. 2008; Yamamichi et al.

343 2015). Finally, organismal stoichiometry is shaped by the evolutionary history (L3) of a given

344 taxon, which can influence both immediate responses of organisms to environmental conditions

345 (i.e., elemental plasticity) and shape species and population differences through space and time 
346 (Elser et al. 2000b; Frisch et al. 2014; Prater et al. 2017). As our study examined the seasonal 347 effects of temperature and food quality (L2) on organismal stoichiometry (L1) of two separate 348 species (L3) in complex natural environments, we are unable to fully differentiate among the 349 effects of all of these factors and their interactions. Nevertheless, our results suggest that 350 temperature is likely to be an important variable controlling organismal elemental content in 351 field populations, despite the possible roles of other factors, as it accounted for a substantial 352 amount of variation in daphnid stoichiometry in both study lakes.

Both temperature and stoichiometric food quality appeared to influence Daphnia biomass 354 production in our study lakes. Biomass in the lower nutrient Wolf Lake was correlated with both 355 food quality and temperature and was highest at low food C:P ratios and moderate temperatures, 356 which occurred in the early spring and fall. Thus, although temperature seemed to predominantly 357 control daphnid stoichiometry in this lake, nutrient availability represents an important factor 358 determining zooplankton production and likely interacts with temperature to influence seasonal 359 patterns in Daphnia biomass in oligo- and mesotrophic systems (Elser et al. 1998; Makino et al. 2002). Daphnia biomass was not related to food quality in Pigeon Lake where seston was P-rich 361 year-round. Instead, biomass peaked at moderate temperatures early in the year and remained 362 low for the remainder of the growing season. We were unable to quantify predation pressure in 363 our study, which could have influenced seasonal variation in Pigeon Lake biomass. Similarly, we 364 did not measure differences in algal taxonomic composition, but daphnid biomass remained low 365 despite high food quantities and was negatively related to algal biomass (Suppl. Fig 2). As 366 cyanobacteria blooms can develop in the mid-summer and persist throughout the growing season 367 in Pigeon Lake, it is possible that either feeding inhibition (Abrams and Walters 1996; DeMott et 368 al. 2001) or reduced growth and reproductive rates due to fatty acid-limitation (Ravet et al., 

true, our results suggest that food quality effects on daphnid nutritional physiology and biomass

371 production may act along a continuum controlled by dietary elemental stoichiometry in

372 oligotrophic systems and switching to physical and/or biochemical regulation under more 373 eutrophic conditions.

In this study, we documented complex relationships between seston food C:P ratios and 375 temperature and consumer elemental metabolism and biomass production over a summer 376 growing season in two separate lake ecosystems. While the correlational nature of our study 377 necessarily limits the strength and breadth of our conclusions, we provide observational evidence 378 that seasonal temperature changes were likely responsible for decoupling producer-consumer 379 stoichiometry and altering consumer elemental-biochemical investment in natural populations. 380 These observations provide important insights for stoichiometric theory as they might partially 381 explain contrasting responses to elemental limitation among species adapted to different habitats 382 (Bullejos et al., 2014; Zhang et al., 2016) and could account for the weak relationships 383 sometimes found between consumer biochemistry and elemental composition (Wilder and 384 Jeyasingh 2016). However, metabolic changes in our populations did not translate into straight385 forward predictable biomass responses in either lake highlighting current theoretical limitations 386 in linking organismal-level physiology and life-history to higher-order ecological processes 387 (Cherif et al. 2017). Moving ahead, careful laboratory studies in conjunction with manipulative 388 field-based experiments are needed to better understand these cross-scale dynamics while 389 controlling for and estimating the relative influence of other important ecological factors. These 390 studies will allow for temperature effects on consumer metabolic physiology to be more fully 391 integrated into existing stoichiometric models (e.g., Cross et al. 2015) to better predict how 
392 consumer population dynamics and ecosystem functions may change under increasingly variable 393 climatic conditions occurring across the planet.

394 Acknowledgements

395 We thank Andrew Scott, Beatrice Chan, Colleen Middleton, Charlotte Narr, and Graham 396 Blakelock for lab and field help and Rich Vogt, Andrea Conine, and two anonymous reviewers

397 for their insightful comments, which helped to improve the manuscript. This work was supported 398 by a NSERC Discovery Grant to PCF and by OGS scholarships to CP and NDW. 


\section{References}

Abrams, P. A., and C. J. Walters. 1996. Invulnerable prey and the paradox of enrichment. Ecology 77: 1125-1133.

Acharya, K., M. Kyle, and J. J. Elser. 2004. Biological stoichiometry of Daphnia growth: An ecophysiological test of the growth rate hypothesis. Limnol. Oceanogr. 49: 656-665. doi:10.4319/lo.2004.49.3.0656

Alcaraz, M., R. Almeda, E. Saiz, A. Calbet, C. M. Duarte, S. Agusti, R. Santiago, and A. Alonso. 2013. Effects of temperature on the metabolic stoichiometry of Arctic zooplankton. Biogeosciences 10: 689-697. doi:10.5194/bg-10-689-2013

Allen, A. P., and J. F. Gillooly. 2009. Towards an integration of ecological stoichiometry and the metabolic theory of ecology to better understand nutrient cycling. Ecol. Lett. 12: 369-384. doi:10.1111/j.1461-0248.2009.01302.x

Andersen, T. 1997. Pelagic Nutrient Cycles: Herbivores as Sources and Sinks, Springer.

APHA. 1992. APHA Method 4500-P: Standard Methods for the Examination of Water and Wastewater, 18th ed. A.E. Greenberg, L.S. Clesceri, and A.D. Eaton [eds.]. American Public Health Associattion.

Brown, J. H., J. F. Gillooly, A. P. Allen, V. M. Savage, and G. B. West. 2004. Toward a metabolic theory of ecology. Ecology 85: 1771-1789.

Bullejos, F. J., P. Carillo, E. Gorokhova, J. M. Medina-Sanchez, and M. Villar-Argaiz. 2014. Nucleic acid content in crustacean zooplankton : Bridging metabolic and stoichiometric predictions. PLoS One 9: e86493. doi:10.1371/journal.pone.0086493

Carlson, R. E. 1977. A trophic state index for lakes. Limnol. Oceanogr. 22: 361-369.

Carpenter, S. R., J. F. Kitchell, and J. R. Hodgson. 1985. Cascading trophic interactions and lake 
productivity. Bioscience 35: 634-639. doi:10.2307/1309989

Cebrian, J., J. B. Shurin, E. T. Borer, B. J. Cardinale, J. T. Ngai, M. D. Smith, and W. F. Fagan. 2009. Producer nutritional quality controls ecosystem trophic structure. PLoS One 4: 1-5. doi:10.1371/journal.pone.0004929

Cherif, M., C. Faithfull, J. Guo, C. L. Meunier, J. Sitters, W. Uszko, and F. Rivera Vasconcelos. 2017. An operational framework for the advancement of a molecule-to-biosphere stoichiometry theory. Front. Mar. Sci. 4. doi:10.3389/fmars.2017.00286

Crins, W., P. Gray, P. Uhlig, and M. Wester. 2009. The Ecosystems of Ontario, Part 1: Ecozones and Ecoregions. Ministry of Natural Resources and Forestry: SIB TER IMA TR-01.

Cross, W. F., J. M. Hood, J. P. Benstead, A. D. Huryn, and D. Nelson. 2015. Interactions between temperature and nutrients across levels of ecological organization. Glob. Chang. Biol. 21: 1025-1040. doi:10.1111/gcb.12809

Darchambeau, F., P. J. Faerøvig, and D. O. Hessen. 2003. How Daphnia copes with excess carbon in its food. Oecologia 136: 336-346. doi:10.1007/s00442-003-1283-7

DeMott, W. R., R. D. Gulati, and E. Van Donk. 2001. Daphnia food limitation in three hypereutrophic Dutch lakes: Evidence for exclusion of large-bodied species by interfering filaments of cyanobacteria. Limnol. Oceanogr. 46: 2054-2060. doi:10.4319/lo.2001.46.8.2054

DeMott, W. R., B. J. Pape, and A. J. Tessier. 2004. Patterns and sources of variation in Daphnia phosphorus content in nature. Aquat. Ecol. 38: 433-440. doi:10.1023/B

Dickman, E. M., J. M. Newell, M. J. González, and M. J. Vanni. 2008. Light, nutrients, and food-chain length constrain planktonic energy transfer efficiency across multiple trophic levels. Proc. Natl. Acad. Sci. U. S. A. 105: 18408-18412. doi:10.1073/pnas.0805566105 
Elser, J. J., K. Acharya, M. Kyle, and others. 2003. Growth rate-stoichiometry couplings in diverse biota. Ecol. Lett. 6: 936-943. doi:10.1046/j.1461-0248.2003.00518.x

Elser, J. J., T. H. Chrzanowski, R. W. Sterner, and K. H. Mills. 1998. Stoichiometric constraints on food-web dynamics: A whole-lake experiment on the Canadian Shield. Ecosystems 1: 120-136. doi:10.1007/s100219900009

Elser, J. J., D. R. Dobberfuhl, N. A. MacKay, and J. H. Schampel. 1996. Organism size, life history, and N:P stoichiometry: Toward a unified view of cellular and ecosystem processes. Bioscience 46: 674-684. doi:10.2307/1312897

Elser, J. J., W. F. . Fagan, R. F. Denno, and others. 2000a. Nutritional constraints in terrestrial and freshwater food webs. Nature 408: 578-580. doi:10.1038/35046058

Elser, J. J., W. J. O'Brien, Dobberfuhl D.R., and T. E. Dowling. 2000b. The evolution of ecosystem processes: Growth rate and elemental stoichiometry of a key herbivore in temperate and arctic habitats. J. Evol. Biol. 13: 845-853. doi:10.1046/j.14209101.2000.00215.x

Elser, J. J., R. W. Sterner, E. Gorokhova, and others. 2000c. Biological stoichiometry from genes to ecosystems. Ecol. Lett. 3: 540-550.

Evjemo, J. O., T. L. Danielsen, and Y. Olsen. 2001. Losses of lipid, protein and n - 3 fatty acids in enriched Artemia franciscana starved at different temperatures. Aquaculture 193: 65-80.

Frisch, D., P. K. Morton, P. R. Chowdhury, B. W. Culver, J. K. Colbourne, L. J. Weider, and P. D. Jeyasingh. 2014. A millennial-scale chronicle of evolutionary responses to cultural eutrophication in Daphnia. Ecol. Lett. 17: 360-8. doi:10.1111/ele.12237

Frost, P. C., D. Ebert, and V. H. Smith. 2008. Bacterial infection changes the elemental composition of Daphnia magna. J. Anim. Ecol. 77: 1265-1272. doi:10.1111/j.1365- 
2656.2008.01438.x

Frost, P. C., M. A. Evans-White, Z. V. Finkel, T. C. Jensen, and V. Matzek. 2005. Are you what you eat? Physiological constraints on organismal stoichiometry in an elementally imbalanced world. Oikos 109: 18-28. doi:10.1111/j.0030-1299.2005.14049.x

Gardner, W. S., W. A. Frez, E. A. Cichocki, and C. C. Parrish. 1985. Micromethod for lipids in aquatic invertebrates. Limnol. Oceanogr. 30: 1099-1105.

Ger, K. A., P. Urrutia-Cordero, P. C. Frost, L. A. Hansson, O. Sarnelle, A. E. Wilson, and M. Lurling. 2016. The interaction between cyanobacteria and zooplankton in a more eutrophic world. Harmful Algae 54: 128-144. doi:10.1016/j.hal.2015.12.005

Gillooly, J. F., J. H. Brown, G. B. West, V. M. Savage, and E. L. Charnov. 2001. Effects of size and temperature on metabolic rate. Science 293: 2248-2251.

Gorokhova, E., T. E. Dowling, L. J. Weider, T. J. Crease, and J. J. Elser. 2002. Functional and ecological significance of rDNA intergenic spacer variation in a clonal organism under divergent selection for production rate. Proc. R. Soc. B 269: 2373-2379. doi:10.1098/rspb.2002.2145

Haney, J. F., and D. J. Hall. 1973. Sugar Coated Daphnia: A preservation technique for Cladocera. Limnol. Oceanogr. 18: 331-333.

Hessen, D. O., E. Van Donk, and R. Gulati. 2005. Seasonal seston stoichiometry: Effects on zooplankton in cyanobacteria-dominated lakes. J. Plankton Res. 27: 449-460. doi:10.1093/plankt/fbi018

Hicks, A. L., and P. C. Frost. 2011. Shifts in aquatic macrophyte abundance and community composition in cottage developed lakes of the Canadian Shield. Aquat. Bot. 94: 9-16. doi:10.1016/j.aquabot.2010.09.005 
Kreeger, D. A., C. E. Goulden, S. S. Kilham, S. G. Lynn, S. Datta, and S. J. Interlandi. 1997. Seasonal changes in the biochemistry of lake seston. Freshw. Biol. 38: 539-554. doi:10.1046/j.1365-2427.1997.00233.x

Loladze, I., and J. J. Elser. 2011. The origins of the Redfield nitrogen-to-phosphorus ratio are in a homoeostatic protein-to-rRNA ratio. Ecol. Lett. 14: 244-250. doi:10.1111/j.14610248.2010.01577.x

Loladze, I., Y. Kuang, and J. J. Elser. 2000. Stoichiometry in producer-grazer systems: Linking energy flow with element cycling. Bull. Math. Biol. 62: 1137-1162. doi:10.1006/bulm.2000.0201

Makino, W., Q. Gong, and J. Urabe. 2011. Stoichiometric effects of warming on herbivore growth: experimental test with plankters. Ecosphere 2: 1-11. doi:10.1890/ES11-00178.1

Makino, W., J. Urabe, J. J. Elser, and C. Yoshimizu. 2002. Evidence of phosphorus-limited individual and population growth of Daphnia in a Canadian Shield lake. Oikos 96: 197205. doi:10.1034/j.1600-0706.2002.960201.x

McCauley, E. 1984. The estimation of the abundance and biomass of zooplankton in samples, p. 228-265. In J.A. Downing and F.H. Rigler [eds.], A Manual for the Assessment of Secondary Productivity in Fresh Waters. Blackwell Scientific Publishers.

McCauley, E., and J. Kalff. 1981. Empirical relationships between phytoplankton and zooplankton biomass in lakes. Can. J. Fish. Aquat. Sci. 38: 458-463.

McFeeters, B. J., and P. C. Frost. 2011. Temperature and the effects of elemental food quality on Daphnia. Freshw. Biol. 56: 1447-1455. doi:10.1111/j.1365-2427.2011.02586.x

Moody, E. K., A. T. Rugenski, J. L. Sabo, B. L. Turner, and J. J. Elser. 2017. Does the growth rate hypothesis apply across temperatures? Variation in the growth rate and body 
phosphorus of neotropical benthic grazers. Front. Environ. Sci. 5: 1-11. doi:10.3389/fenvs.2017.00014

Pantel, J. H., D. E. Pendleton, A. Walters, and L. A. Rogers. 2014. Linking environmental variability to population and community dynamics, p. 119-131. In P.. Kemp [ed.], Eco-Das IX. Association for the Sciences of Limnology and Oceanography.

Petchey, O. L., P. T. Mcphearson, T. M. Casey, and P. J. Morin. 1999. Environmental warming alters food-web structure and ecosystem function. Nature 402: 69-72.

Prater, C., N. D. Wagner, and P. C. Frost. 2017. Interactive effects of genotype and food quality on consumer growth rate and elemental content. Ecology 98: 1399-1408. doi:10.1002/ecy.1795

Ravet, J. L., J. Persson, and M. T. Brett. 2012. Threshold dietary polyunsaturated fatty acid concentrations for Daphnia pulex growth and reproduction. Inl. Waters 2: 199-209. doi:10.5268/IW-2.4.546

Rizzo, A. M. L., and G. J. Szekely. 2008. Energy: E-statistics (energy statistics).

Savage, V. M., J. F. Gillooly, J. H. Brown, G. B. West, and E. L. Charnov. 2004. Effects of body size and temperature on population growth. Am. Nat. 163: 431-441.

Sievers, A., M. Beringer, M. V. Rodnina, and R. Wolfenden. 2004. The ribosome as an entropy trap. Proc. Natl. Acad. Sci. 101: 7897-7901.

Sommer, U., R. Adrian, L. De Senerpont Domis, and others. 2012. Beyond the plankton ecology group (PEG) model: Mechanisms driving plankton succession. Annu. Rev. Ecol. Evol. Syst. 43: 429-448. doi:10.1146/annurev-ecolsys-110411-160251

Sommer, U., Z. M. Gliwicz, W. Lampert, and A. Duncan. 1986. The PEG-model of seasonal succession of planktonic events in fresh waters. Arch. für Hydrobiol. 106: 433-471. 
Sterner, R. W., T. Andersen, J. J. Elser, D. O. Hessen, J. M. Hood, E. McCauley, and J. Urabe. 2008. Scale-dependent carbon: nitrogen: phosphorus seston stoichiometry in marine and freshwaters. Limnol. Oceanogr. 53: 1169-1180. doi:10.4319/lo.2008.53.3.1169

Sterner, R. W., D. D. Hagemeier, W. L. Smith, R. F. Smith, L. Smith, and F. Smith. 1993. Phytoplankton nutrient limitation and food quality for Daphnia. Limnol. Oceanogr. 38: $857-871$.

Székely, G. J., and M. L. Rizzo. 2009. Brownian distance covariance. Ann. Appl. Stat. 3: 12361265. doi:10.1214/09-AOAS312

Toseland, A., S. J. Daines, J. R. Clark, and others. 2013. The impact of temperature on marine phytoplankton resource allocation and metabolism. Nat. Clim. Chang. 3: 1-6. doi:10.1038/nclimate1989

Ventura, M., and J. Catalan. 2005. Reproduction as one of the main causes of temporal variability in the elemental composition of zooplankton. Limnol. Oceanogr. 50: 2043-2056. doi:10.4319/lo.2005.50.6.2043

Wagner, N. D., H. Hillebrand, A. Wacker, and P. C. Frost. 2013. Nutritional indicators and their uses in ecology. Ecol. Lett. 16: 535-544. doi:10.1111/ele.12067

Wagner, N. D., B. P. Lankadurai, M. J. Simpson, A. J. Simpson, and P. C. Frost. 2015. Metabolomic differentiation of nutritional stress in an aquatic invertebrate. Physiol. Biochem. Zool. 88: 43-52. doi:10.1086/679637

Wilder, S. M., and P. D. Jeyasingh. 2016. Merging elemental and macronutrient approaches for a comprehensive study of energy and nutrient flows. J. Anim. Ecol. 85: 1427-1430. doi:10.1111/1365-2656.12573

Woods, H. A., W. Makino, J. B. Cotner, S. E. Hobbie, J. F. Harrison, K. Acharya, and J. J. Elser. 
2003. Temperature and the chemical composition of poikilothermic organisms. Funct. Ecol. 17: 237-245.

Yamamichi, M., C. L. Meunier, A. Peace, C. Prater, and M. A. Rúa. 2015. Rapid evolution of a consumer stoichiometric trait destabilizes consumer-producer dynamics. Oikos 124: 960969. doi:10.1111/oik.02388

Zhang, C., M. Jansen, L. De Meester, R. Stoks, and S. Behmer. 2016. Energy storage and fecundity explain deviations from ecological stoichiometry predictions under global warming and size-selective predation. J. Anim. Ecol. 85: 1431-1441. doi:10.1111/13652656.12531 


\section{Figure Captions}

Fig 1. Seasonal variation in seston carbon:phosphorus $(\mathrm{C}: \mathrm{P})$ ratios, lake temperature, and Daphnia body C:P ratios. Weekly means \pm standard error are plotted for C:P ratios. Top (white) and bottom (light grey) seston C:P values and top water column temperature values are shown for Wolf Lake. Water column integrated seston C:P and temperature values are displayed for Pigeon Lake (dark grey).

Fig 2. Changes in Daphnia body elemental composition across seston stoichiometry and temperature gradients in Wolf Lake. Distance correlations are reported for: A) seston carbon:phosphorus $(\mathrm{C}: \mathrm{P})$ ratios and daphnid body \%C, B) temperature and daphnid body \%C, $\mathrm{C})$ seston C:P ratios and daphnid body \%P, D) temperature and daphnid body \%P, E) seston C:P ratios and daphnid body $\mathrm{C}: \mathrm{P}$ ratios, and $\mathrm{F}$ ) temperature and daphnid body $\mathrm{C}: \mathrm{P}$ ratios. $P$-values and correlation coefficients (D) are reported for each correlation.

Fig 3. Changes in Daphnia body elemental composition across seston stoichiometry and temperature gradients in Pigeon Lake. Distance correlations are reported for: A) seston carbon:phosphorus $(\mathrm{C}: \mathrm{P})$ ratios and daphnid body \%C, B) temperature and daphnid body \%C, C) seston $\mathrm{C}: \mathrm{P}$ ratios and daphnid body $\% \mathrm{P}, \mathrm{D})$ temperature and daphnid body $\% \mathrm{P}, \mathrm{E}$ ) seston $\mathrm{C}: \mathrm{P}$ ratios and daphnid body $\mathrm{C}: \mathrm{P}$ ratios, and $\mathrm{F}$ ) temperature and daphnid body $\mathrm{C}: \mathrm{P}$ ratios. $P$-values and correlation coefficients (D) are reported for each correlation.

Fig 4. Correlations between temperature, Daphnia body RNA content, and body elemental composition. Distance correlations are shown for: A\&B) temperature and daphnid body RNA content, C\&D) daphnid body phosphorus (\%P) content and body \%RNA, and E\&F) daphnid body $\mathrm{C}: \mathrm{P}$ ratios and the proportion of body $\mathrm{P}$ bound in RNA (\%P-RNA). $P$-values and 
correlation coefficients (D) are reported separately for each lake. Wolf Lake values are shown in white, and Pigeon Lake values are displayed in grey.

Fig 5. Correlations between temperature, Daphnia body lipid content, and body elemental composition. Distance correlations are shown for: A\&B) temperature and daphnid body \%lipid, C\&D) daphnid body carbon (\%C) content and body \%lipid, and E\&F) daphnid body C:phosphorus (P) ratios and body \%lipid. $P$-values and correlation coefficients (D) are reported separately for each lake. Wolf Lake values are shown in white, and Pigeon Lake values are displayed in grey.

Fig 6. Changes in Daphnia biomass across the growing season and correlations between seston nutrient content, temperature, and daphnid biomass production. Weekly means \pm standard error are plotted for seasonal changes $(\mathrm{A} \& \mathrm{~B})$. Scatterplots and distance correlations are shown for: $\mathrm{C} \& \mathrm{D})$ seston carbon:phosphorus $(\mathrm{C}: \mathrm{P})$ ratios and daphnid biomass and between $\mathrm{E} \& \mathrm{~F})$ temperature and daphnid biomass. $P$-values and correlation coefficients (D) are reported separately for each lake. Wolf Lake values are shown in white, and Pigeon Lake values are displayed in grey. 
Figure 1.
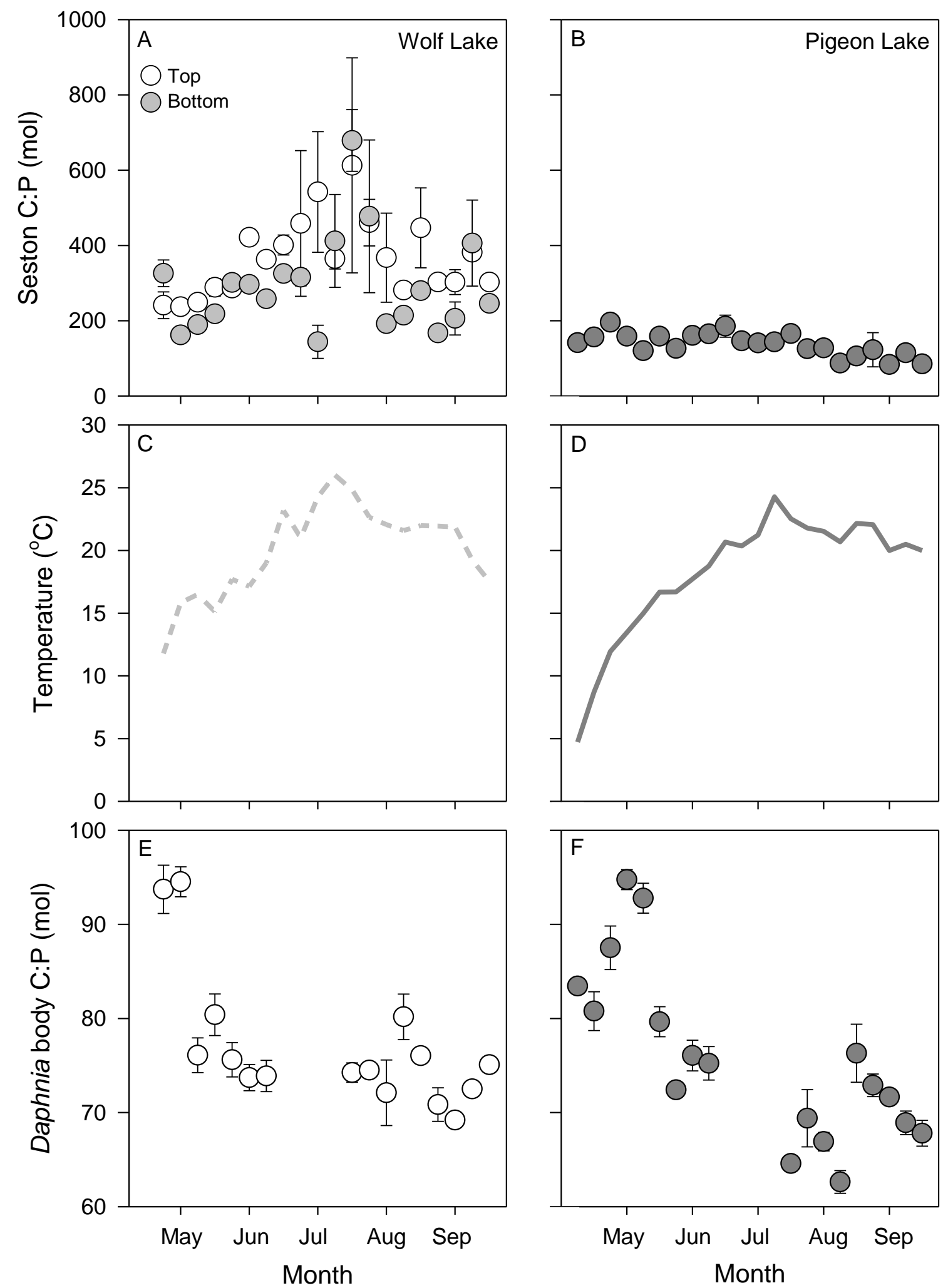
Figure 2.
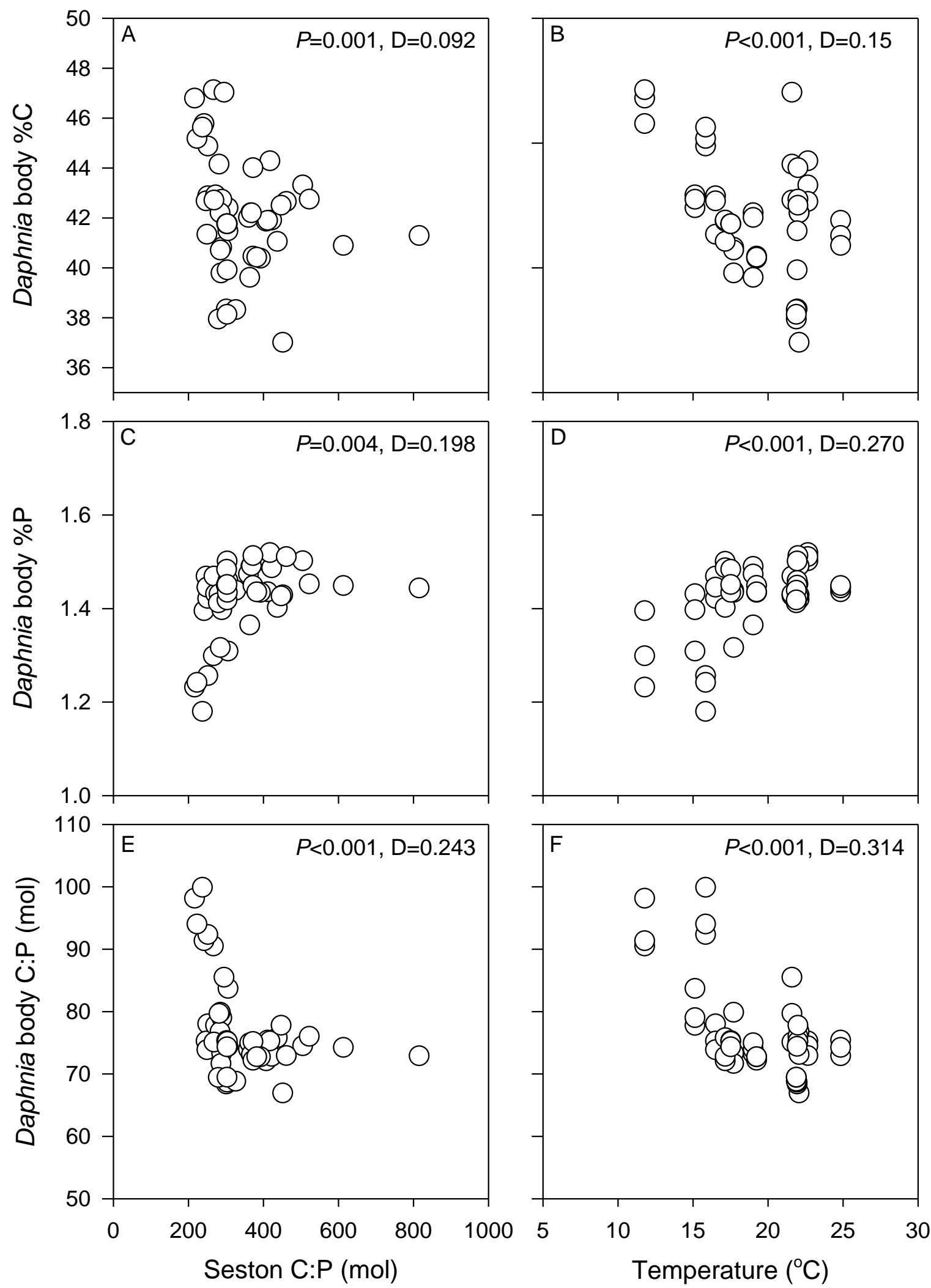
Figure 3.
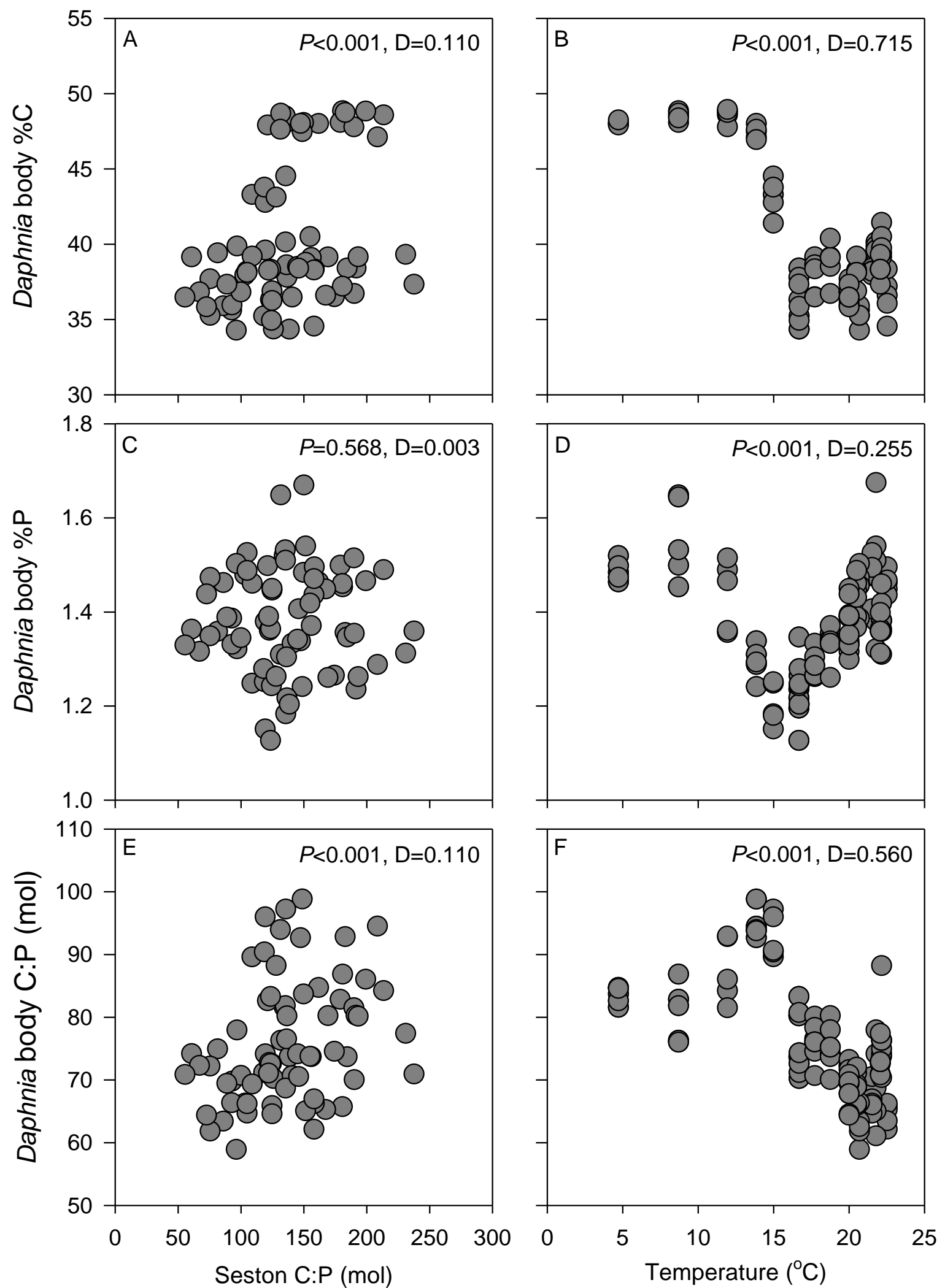
Figure 4.
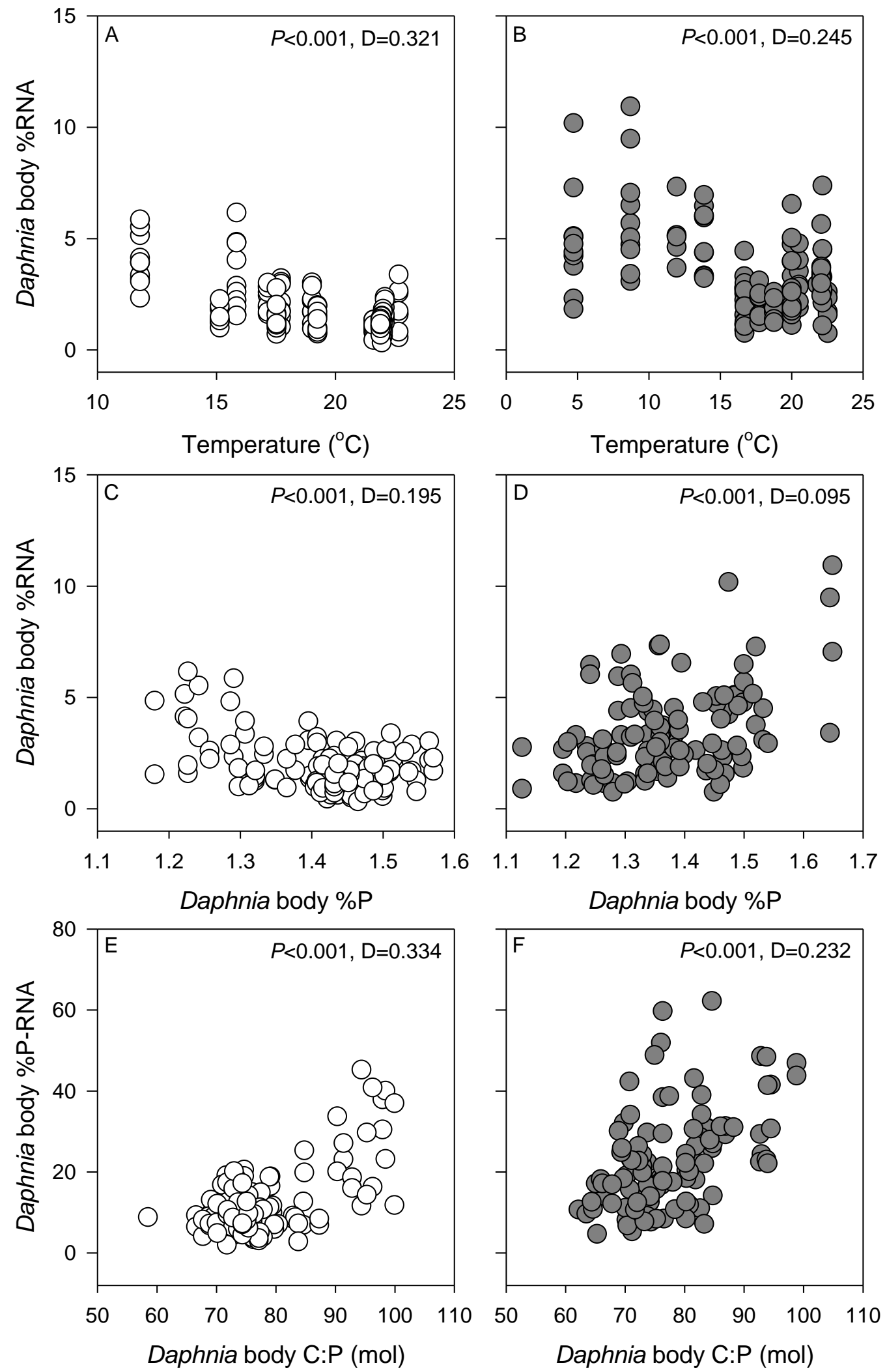
Figure 5
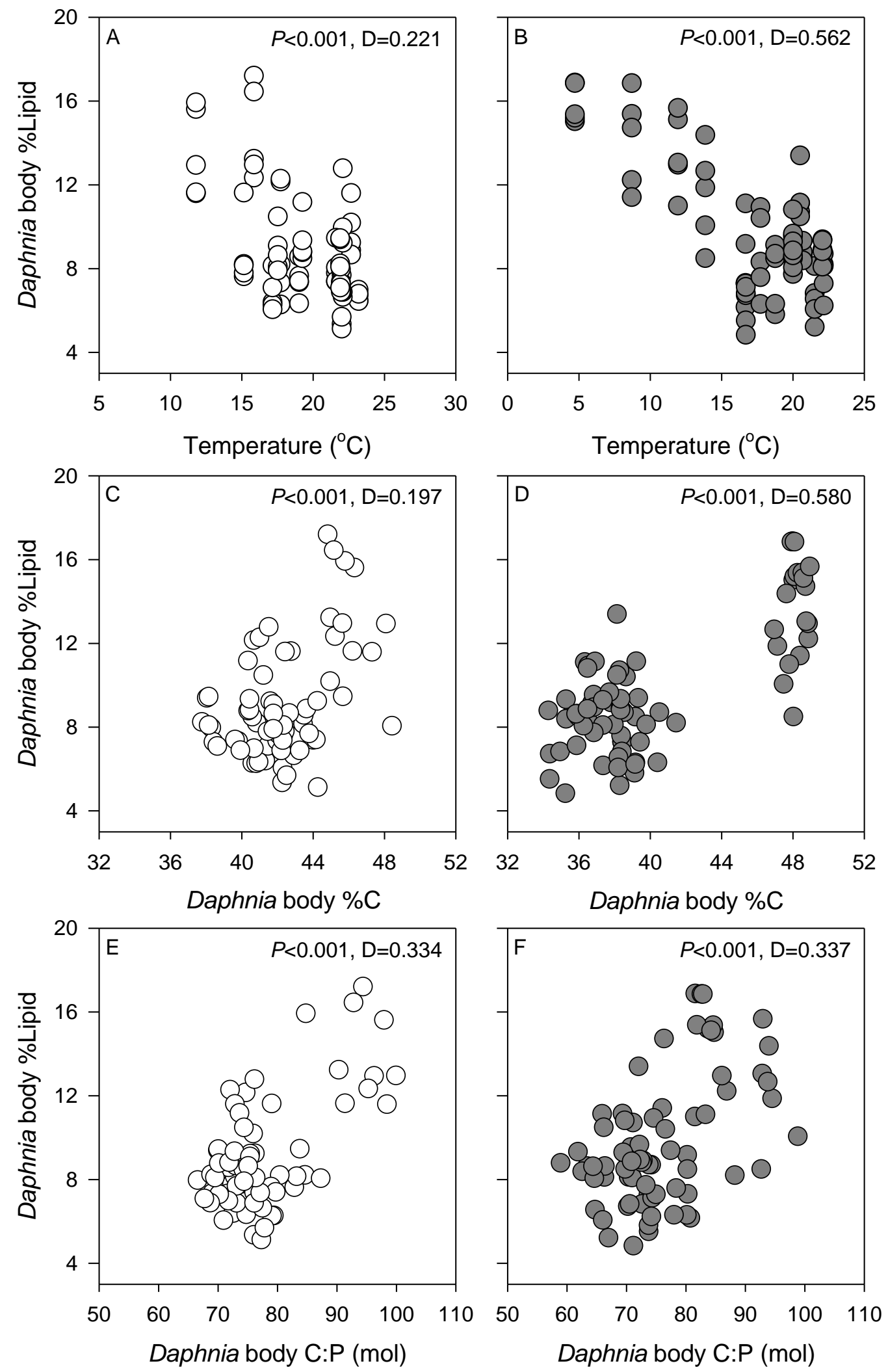
Figure 6.
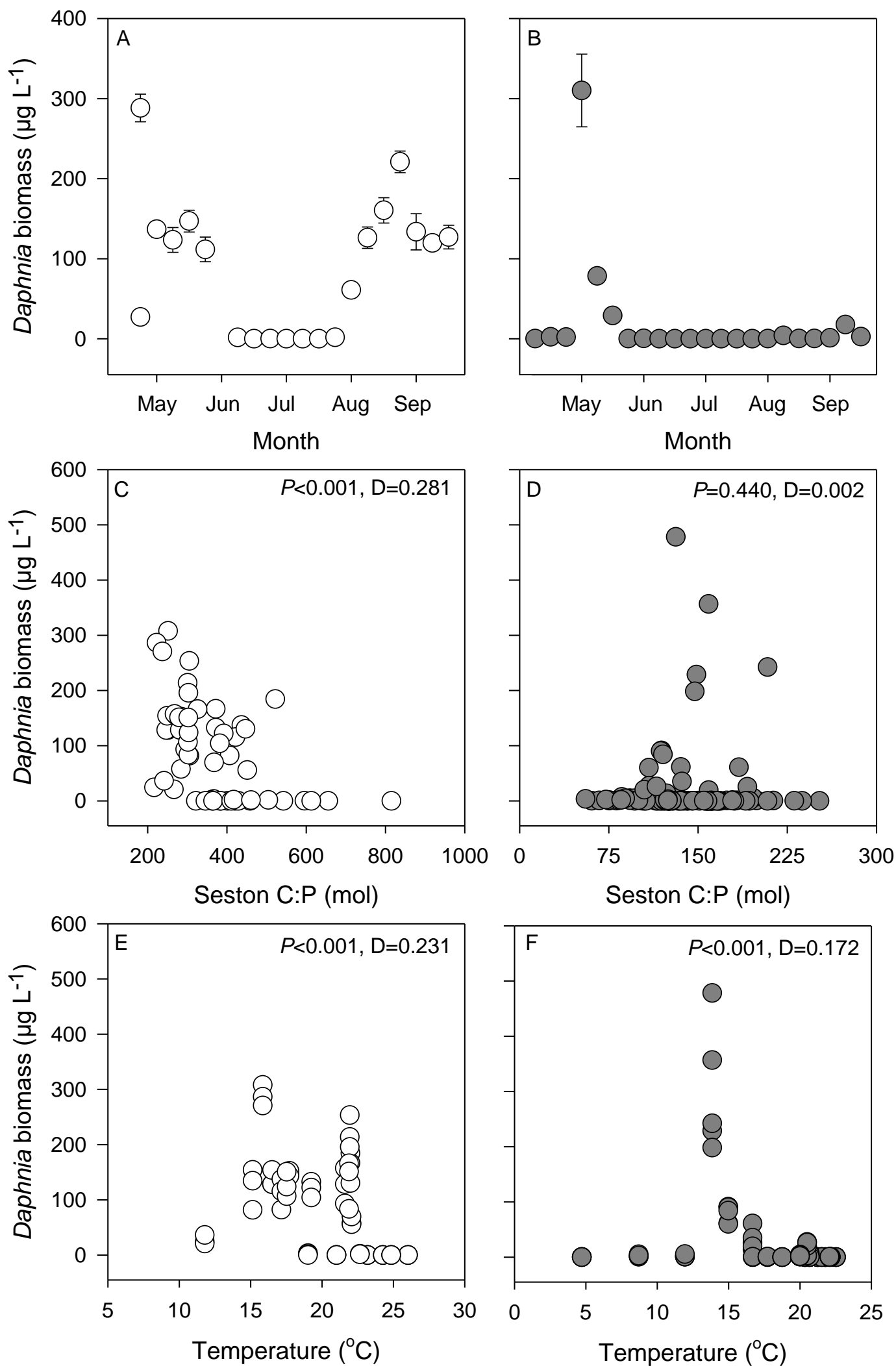
